\title{
CLINIC0-PATHOLOGICAL CHANGES INDUCED IN RATS TREATED WITH AMINE-CURING AGENT FOR EPOXY RESIN, BIS(4-AMIN0-3-METHYLCYCLOHEXYL)METHANE
}

\author{
Susumu OHSHIMA, Toshikatsu SHIBATA, Norihiro SASAKI*, \\ Hirokazu OKUDA*, Harumi NISHIZAWA*, Mamoru OHSAWA*, \\ Michiharu MATSUMOTO* and Eiki NAKAYAMA** \\ Second Department of Pathology, Saitama Medical School, Saitama, Japan. \\ * Occupational Health Service Center, Japan Industrial Safety and Health Associ- \\ ation, Tokyo, Japan \\ ** Japan Bioassay Laboratory, Japan Industrial Safety and Health Association, \\ Kanagawa, Japan.
}

Accepted December 12, 1985

\begin{abstract}
Amine-curing agent for epoxy resin, bis(4-amino-3-methyl-cyclohexyl)methane (commercial name; Laromin $C$ ) has been suspected to have induced in the workers some toxic signs such as collagen disease like scleroderma or polymyositis.

Subacute toxicity of this agent was studied in rats following repeated oral administration. The agent was given orally at 5 dose levels $(25 \mathrm{mg} / \mathrm{kg}$ to 100 $\mathrm{mg} / \mathrm{kg}$ per one dose) for periods ranging from 10 days to 4 weeks. After the completion of administration, clinico-biochemical tests and histopathological examinations were carried out. In a few cases, skeletal muscles and choroid plexus of the brain were examined by electronmicroscopy.

Clinico-biochemical tests revealed some elevation of muscle-derived components such as GOT and CPK as seen in the myopathic diseases. Histologically, various degrees of atrophy, degeneration and regeneration of muscle fibers and a numerical increase of interstitial cells were observed in the skeletal muscles. Electronmicroscopical examination of the gastrocnemius muscle revealed intrasarcoplasmic osmiophilic round-shaped inclusion bodies, sometimes with lamellar structure, which were suggestive of some lipidosis. The epithelial cells of choroid plexus in the brain ventricles represented various
\end{abstract}

連絡先：干 350-04 埼玉県入間郡毛吕山町大字毛吕本郷 38 埼玉医科大学第 2 病理学教室 大島晋 


\section{Susumu OHSHIMA et al.}

degrees of vacuolar changes lightmicroscopically, which were suggested to be dilated smooth endoplasmic reticulum electronmicroscopically.

Although scleroderma-like changes were not observed in our experiments, the results suggest that this amine-curing agent for epoxy resin could be one of the causative agents which induced toxic lesions like some collagen diseases including muscle lesions in the workers. In addition, it is considered that the agent may have systemic toxic effects.

Key words: amine, epoxy resin, scleroderma, polymyositis, collagen disease, toxic myopathy, choroid plexus in the brain, intracytoplasmic inclusion body, experimental lipidosis.

\section{INTRODUCTION}

Arguments about the toxicity of epoxy resin have been focused on primary irritating effects untill now (Hine, C. H. et al., 1981). In 1974-1976, however, many patients with some lesions which were thought to be resulted from toxic effects of epoxy resin were found among the workers at an electrical manufactory in Japan, and special attentions were paid to the toxic effects of the resin because most of the patients showed such collagen disease-like disorders as scleroderma or polymyositis (Yamakage, A. et al., 1980). Thereafter, some efforts to clarify the nature of the toxic effects of the resin were made at several institutes. Then the allergenicity of the agent was revealed (Matsushita, T. et al.1980) and scleroderma-like changes were induced by the aminecuring agent of the resin in experimental animals (Yamakage, A. et al., 1980, Ishikawa, H. et al., 1980). But until now, the muscular disease has not been reproduced experimentally and the detailed relationship between the toxic lesions in the workers and the suspected agent has not been established.

In our reserch group, attention was paid to the amine-curing agent, bis(4-amino- 3 -methylcyclohexyl)methane (Fig. 1) which was thought to be the most toxic component of the resin, and subacute toxicity of this agent by oral administration to rats was investigated. Consequently, some clinico-biochemical and pathological changes which might have been caused by this agent were observed in the skeletal muscles and brain choroid plexus, and the results of lightmicroscopical studies have been previously reported (Ohshima, S. et al., 1984). In this paper, results of further examination including electronmicroscopical studies were described and some discussions were made about the toxic effects of the agent.

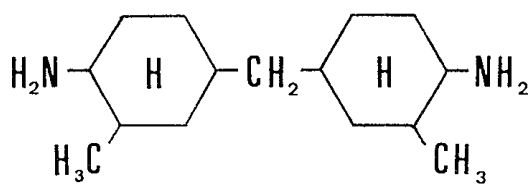

Fig. 1 Chemical structure of bis(4-amino-3-methylcyclohexyl)methane. 


\section{METHODS}

\section{Experiment 1}

Fifty male Fischer rats at 5 weeks of age were used in this study. The agent was diluted with olive oil and administered 20-22 times in 4 weeks. Dose levels for the experimental groups were $75.0,50.0,37.5$ and $25.0 \mathrm{mg} / \mathrm{kg}$ per one dose and the control group received olive oil alone. Ten rats were used for each dosage group, and two animals in the group at $75.0 \mathrm{mg} / \mathrm{kg}$ were killed halfway in the experimental period because they got severely weakened and were taken off from the data. After the completion of administration, the animals were sacrificed under pentobarbital anesthesia and measurement of organ weights, hematological tests (RBC, WBC, Ht, Hb), clinico-biochemical tests (GOT, GPT, Al-P, LAP, BUN) and histopathological examination (liver, kidny, heart, lung, brain, testis, gastrocnemius muscle etc.) were carried out. For histopathological studies, tissue blocks were fixed in a $10 \%$ buffered fomralin(pH 7.4) solution, placed on a routine process, and embedded in paraffin. Thin sections were stained with hematoxylin and eosin(HE), and furthermore, with PAS and Masson-trichrome and with oil red 0 by forzen section when needed.

\section{Experiment 2}

The agent was administered to the animals 8 times in 10 days (group A) or 17 times in 24 days (group B) in the same manner as in experiment 1 . Dose levels in the experimental groups were 100,75 and $50 \mathrm{mg} / \mathrm{kg}$ for group $A$ and 75 and $50 \mathrm{mg} / \mathrm{kg}$ for group B, respectively. Five rats were used for each dosage group. After the completion of administration, clinico-biochemical tests (CPK, MAO, creatine, creatinine) and histopathological examination (liver, kidney, heart, lung, brain, skeletal muscle, back skin, etc.) were carried out. And the gestrocnemius muscle and the brain choroid plexus were examined electronmicroscopically in two animals of each dosage group. Lightmicroscopical studies of the skeletal muscles were made on the gastrocnemius, quadriceps femoris, triceps brachii and intercostal muscles. The method for lightmicroscopical studies was the same an in experiment 1. For electronmicroscopical observation of the gestrocnemius muscle and the brain choroid plexus, tiny pieces of the tissues were fixed in $2 \%$ glutaraldehyde, postfixed in $1 \%$ osmium tetraoxide at $\mathrm{pH} 7.4$, dehydrated in alcohol series and embedded in Epon. Ultrathin sections were stained with uranyl acetate and lead citrate and observed with JEM 100-C and 100-S electron microscopes.

\section{RESULTS}

\section{Clinical observations}

During the administration period in both experiments, the animals showed a suppression of body weight gain depending on the dose levels and exhibited weakness of the limb muscle, especially in the higher dosage groups. 
2. Hematological and serum biochemical examinations

The detailed data of hematological and serum biochemical examinations have been reported previously (Ohshima, S. et al., 1984), and the summarized descriptions were as follows.

In the hematological tests performed only in experiment 1 , significant dercease of leukocyte count was noted in the experimental groups. In the clinico-biochemical tests, significant increase of GOT and decrease of Al-P were observed in the experimental groups in experiment 1 , and MAO showed significant increase and the value of $\mathrm{CPK}$ and creatine showed a tendency to increase in experiment 2 .

\section{Histopathological examinations}

In both experiments, histological changes were observed mainly in the skeltal muscles and brain choroid plexus.

3-a. Lightmicroscopical changes in the skeletal muscles

In the higher dosage groups, various degrees of atrophy and degenerative or regenerative changes of muscle fibers were observed with increased numbers of interstitial fibroblasts. Especially in the highest dosage group in experiment 1, severe muscular damage was observed and increase of interstitial mesenchymal cells was prominent (Photo 1-a). Nuclei of muscle cells were mostly enlarged in the damaged areas, often arranged in chains in the longitudinal section and internalized in the cross section, which indicated regeneration of myofibers (Photo 1-b). Necrotic myofibers in which striations disappeared were also observed. Mild infiltration of inflammatory cells such as lymphocytes was also seen. Small vacuoles, positive to Oil red 0 stain, were frequently obsereved in the muscle fibers (Photo $1-c)$. These vacuoles were recognized as a number of dark granules in the semi-thin epon sections stained with toluidine blue (Photo 1-d), and incidence of this granules in the muscle fibers was nearly dose-dependent (Table 1). The changes were generally milder in experiment 2 than in experiment

Table 1 Incidence of dark granules in the semi-thin sections of the gastrocnemius muscle fibers stained with toluidine blue in experiment 2.

\begin{tabular}{cc}
\hline \hline Groups & Numbers of dark granules $\left(/ 10^{4} \mu \mathrm{m}^{2}\right)^{*}$ \\
\hline A-100 mg/kg & $102 \pm 38$ \\
$75 " \prime$ & $34 \pm 13$ \\
$50 "$ & $7 \pm 5$ \\
control & 0 \\
\hline B-75 mg/kg & $82 \pm 12$ \\
$50 \quad$ & $29 \pm 13$ \\
control & 0 \\
\hline
\end{tabular}

*Specimens were photographed and dark granules were counted in $1 \times 10^{2} \mu \mathrm{m}$ randomly 5 areas per each case and two cases in each group. 

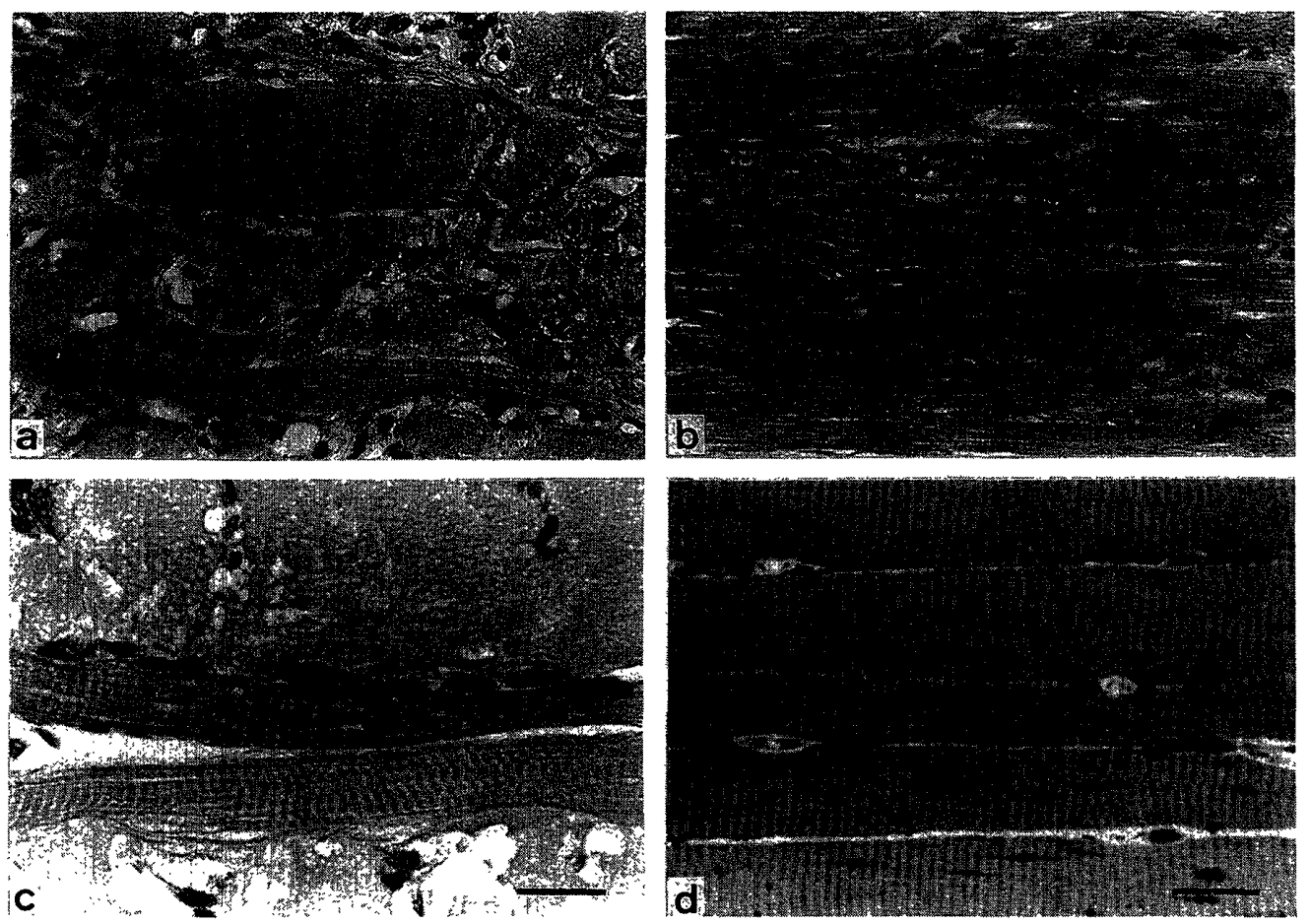

Photo 1-a. Gastrocnemius muscle in experiment $1(75.0 \mathrm{mg} / \mathrm{kg})$. Degeneration or necrosis of muscle fibers and increase of interstitial cells are promine $t$. The scale is $20 \mu \mathrm{m}$. (HE stain)

Photo 1-b. Gastrocnemius muscle in experiment $2(\mathrm{~A})(100 \mathrm{mg} / \mathrm{kg})$. Nuclei of muscle cells are internalized and arranged in chains on this specimen. The scale is $20 \mu \mathrm{m}$. (HE stain)

Photo 1-c. Gastrocnemius muscle in experiment $1(75.0 \mathrm{mg} / \mathrm{kg})$. Small vacuoles are observed in the muscle fiber located in the center of the picture in which striations are well preserved. The necrotic fibers are also seen in the upper and lower parts of the picture. The scale is $20 \mu \mathrm{m}$. (HE stain)

Photo 1-d. Semi-thin epon section of gastrocnemius muscle in experiment 2(A) (100 $\mathrm{mg} / \mathrm{kg}$ ). Glutaraldehyde-osmium fixation and toluidine blue stain. A number of darkely stained small granules are observed in muscle fiber. The scale is $20 \mu \mathrm{m}$. (HE stain)

1, and the gastrocnemius and quadriceps femoris muscles were more severely damaged than the triceps brachii and intercostal muscles. 
3-b. Electronmicroscopical changes in the gastrocnemius muscle

The myofibers were disrupted irregularly with loosening of myofilaments and dilatation of sarcoplasmic reticulum or mitochondria, especially in severely damaged cases of the higher dasage groups(Photo $2-a$, b). Interstitial mesenchymal cells increased in number with various degrees of production of collagen fibers. In addition to these changes, a number of inclusion bodies with high electron density were obsereved within the sarcoplasm of myofibers (Photo $3-\mathbf{a} \sim \mathbf{c}$ ). These inclusion boies were fundamentally of lamellar structure (Photo 3-b), ranging 0.5 to $2.5 \mu \mathrm{m}$ in diameter. But there were also found bodies with more complex structures of varing sizes and shapes (Photo 3-c), probably resulting from conglomeration of smaller fundamental lamellar bodies or being in the course of their formation and maturation. Single-layered limiting membranes were sometimes discerned enveloping the bodies, but in most cases they were ambiguous. No preferential rule of distribution of the bodies in the myofibers was defined, as they were found in the peripheral as well as in the inner zone of myofibers. In many cases, however, they were encountered to be arranged in groups or in chains among the myofibrils or around the nucleus. In mildly damaged cases, striations of muscle fibers were well preserved, and no particular changes were observed in mitochondria or sarcoplasmic reticulum. But lamellar inclusion bodies described above were also found within the myofibers, even if all other components of the myofibers seemed to be normal. Not only in the myofibers but also in the endothelia of the blood vessels in the interstitium, the lamellar inclusion bodies were found frequently (Photo 3-d). The lamellar bodies appeared to be equivalent to the small vacuoles in the paraffin sections which were positive to fat stain or the dark granules in the semi-thin epon sections.

\section{3-c. Lightmicroscopical changes in the brain choroid plexus}

In the brain choroid plexus, various degrees of swelling and vacuolar degeneration of the epithelial cells were seen in addition to the dilatation and congestion of capillary vessels (Photo $4-\mathbf{a} \sim \mathbf{k}$ ). In the most severely damaged cases, almost all of the epithelial cells were markedly swollen and their cytoplasm was completely occupied by vacuoles. In the mildly damaged cases, swelling of the epithelial cells was slight and only small vacuoles were scattered in the cytoplasm. These changes were clearly dose-dependent and nearly of the same range in experiments 1 and 2 . There were no discernible differences in the changes of the choroid plexus among the lateral, third and fourth ventricles, but sometimes the changes in the lateral and fourth ventricles appeared to be somewhat severer than those in the third ventricle. 

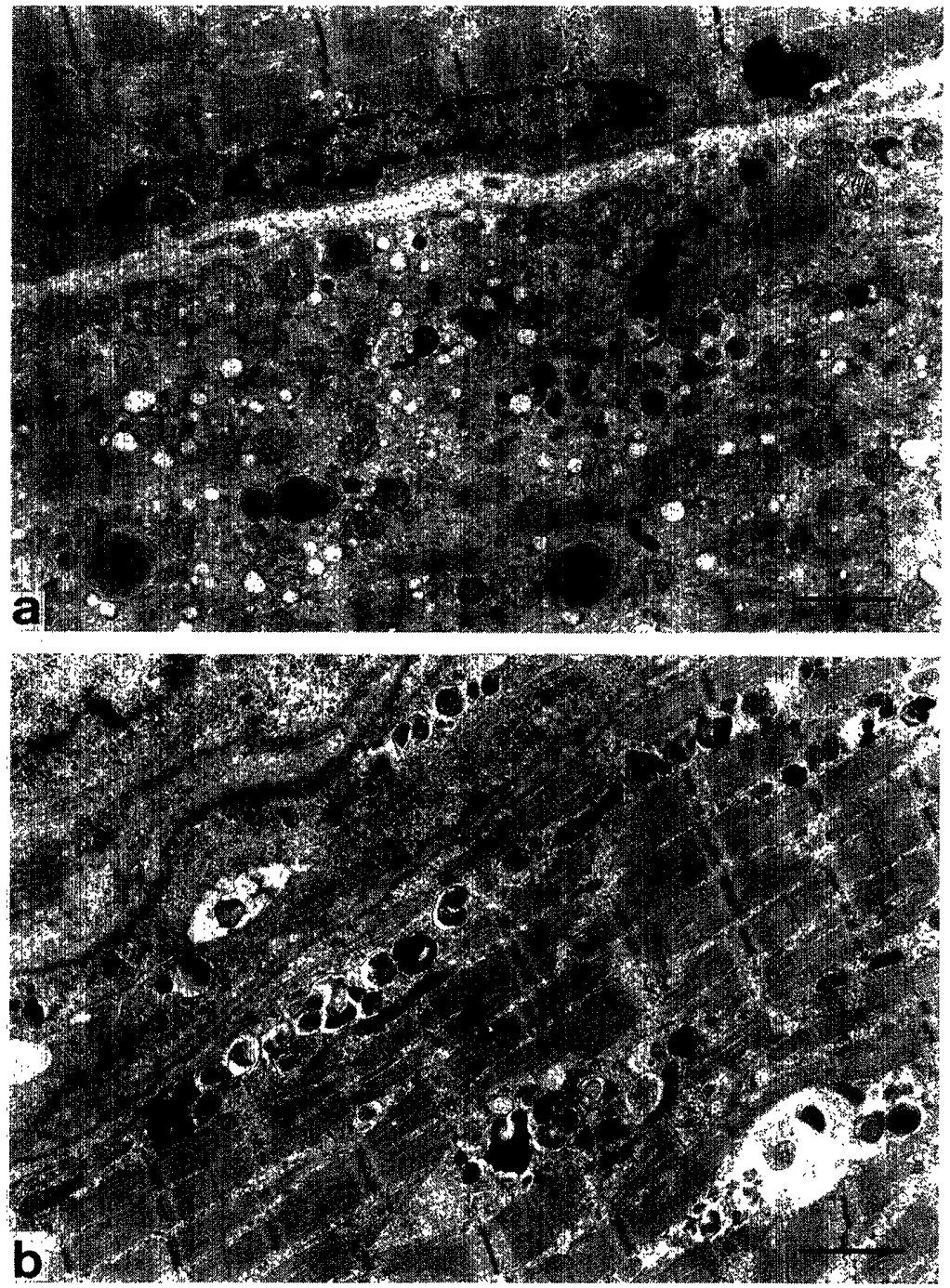

Photo 2-a. Electron micrograph of gastrocnemius muscle in experiment 2 (B) $(75 \mathrm{mg} /$ $\mathrm{kg})$. Disruption of myofibrils with dilatation of mitochondria or sarcoplasmic reticulum is severe and many inclusions of various sizes and forms are seen. The muscle fiber located in the upper parts of the picture is relatively preserved, although electron-dense inclusions are observed at the periphery of the nucleus. The scale is $2 \mu \mathrm{m}$.

Photo 2-b. Electron micrograph of gastrocnemius muscle in experiment $1(75 \mathrm{mg} / \mathrm{kg})$. A number of inclusion bodies of various sizes and forms are observed in sarcoplasm of damaged myofiber. This specimen was prepared from formalin-fixed tissue. The scale is $2 \mu \mathrm{m}$. 

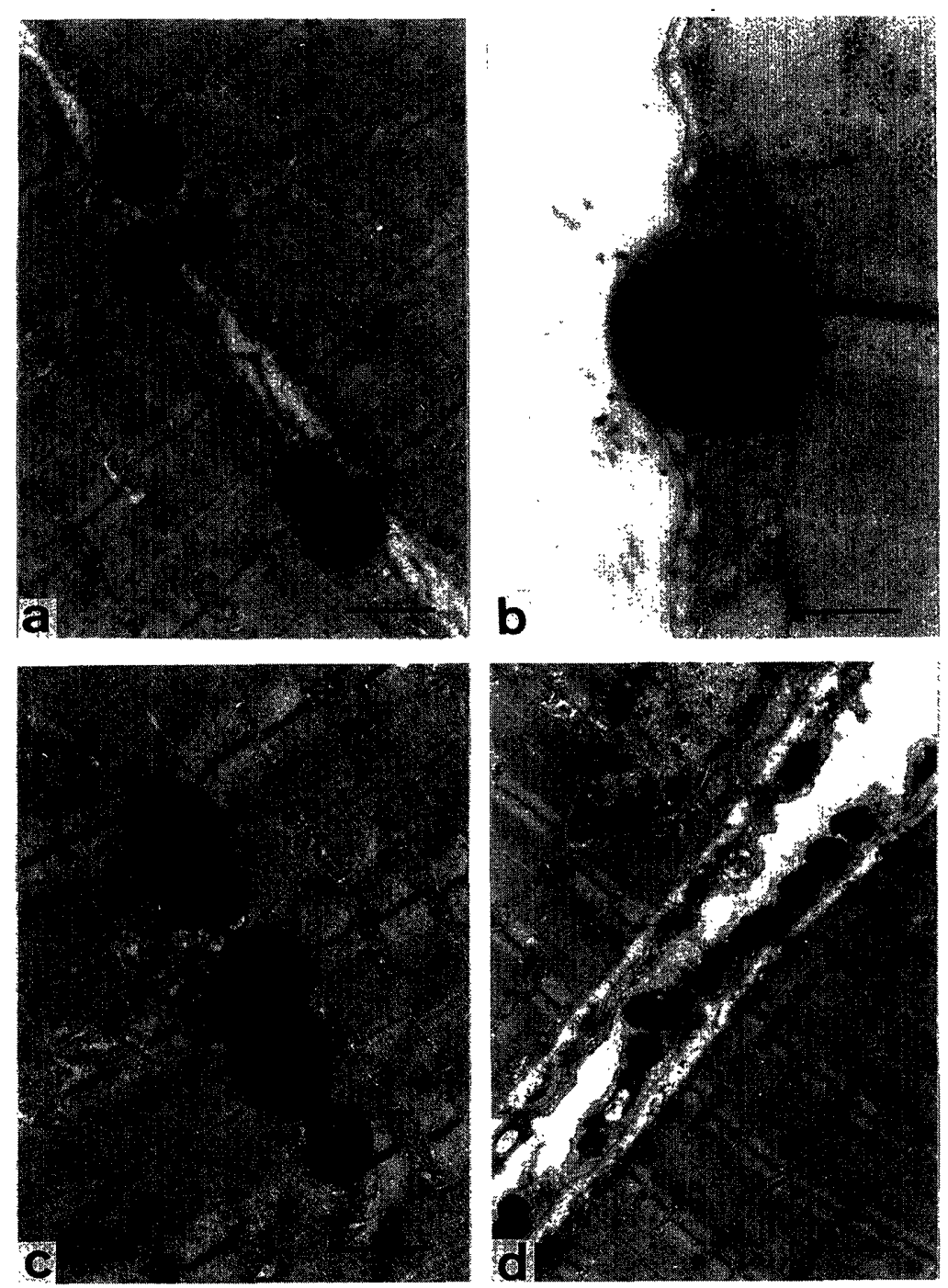

Photo 3-a. Inclusion bodies with high electron density observed in peripheral zone of the muscle fiber. Striations of muscle fibers are well preserved. Gastrocnemius muscle in experiment $2(\mathrm{~A})-100 \mathrm{mg} / \mathrm{kg}$. The scale is $1 \mu \mathrm{m}$.

Photo 3-b. An inclusion body with lamellar structure observed in the same muscle as in Photo 3-a. The scale is $0.5 \mu \mathrm{m}$.

Photo 3-c. Inclusion bodies with more complex structure observed in the inner zone of the same muscle as in Photo $3-a$. The scale is $1 \mu \mathrm{m}$.

Photo 3-d. Inclusion bodies were found frequently in the endothelium of the blood vessles in the interstium as seen in this picture. Gastrocnemius muscle in experiment $2(\mathrm{~A})-75 \mathrm{mg} / \mathrm{kg}$. The scale is $1 \mu \mathrm{m}$. 

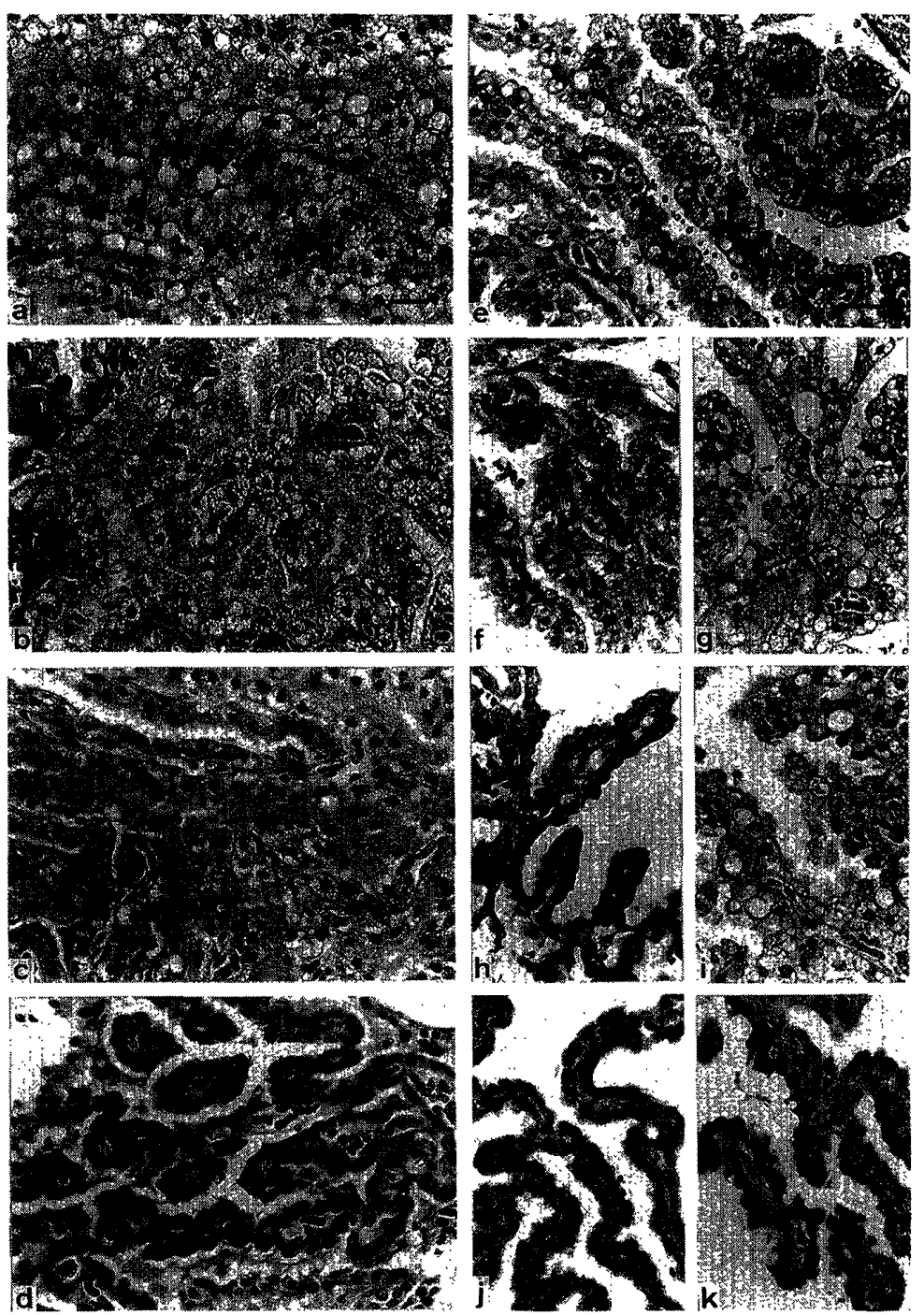

Photo 4-a $\sim$ d. Choroid plexus of lateral ventricle in experiment $1-75.0 \mathrm{mg} / \mathrm{kg}(4-\mathrm{a}), 50$

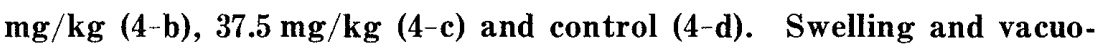
lization of epithelial cells of which degree is dose-dependent are seen. The scale is $20 \mu \mathrm{m}$. (HE stain)

Photo 4-e $\sim$ k. Choroid plexus of lateral ventricle in experiment 2 (A)-100 $\mathrm{mg} / \mathrm{kg}(4-\mathrm{e})$, 2(A) - $75 \mathrm{mg} / \mathrm{kg} \mathrm{(4-f),} \mathrm{2(B)-75} \mathrm{mg/kg} \mathrm{(4-g),} \mathrm{2(A)-50} \mathrm{mg/kg} \mathrm{(4-h),} \mathrm{2(B)-50}$ $\mathrm{mg} / \mathrm{kg}(4-\mathrm{i}), 2(\mathrm{~A})$-control $(4-\mathrm{j})$ and $2(B)$-control $(4-\mathrm{k})$. Degree of the change in epithelial cells is nearly of the same range as in the experiment 1. The scale is $20 \mu \mathrm{m}$. (HE stain) 
3-d. Electronmicroscopical changes in the brain choroid plexus

Vacuolar change of the epithelial cells in the brain choroid plexus was confirmed by electronmicroscopy (Photo 5-a, b). This change seemed to correspond to the vacuolization observed at light microscopic level and to be resulted from dilatation of smooth endplasmic reticlum, as there remained partially mono-layered membranous residues. In addition, the same type of inclusion bodies as observed in the skeletal muscles were also seen in the epithelial cells as well as the endothelial cells of blood capillaries in the interstitium(Photo 5-b). Basement membrane of the epithelial cells showed no particular changes in any dosage group, and no remarkable changes were observed in the ependymal cells covering the inner surface of the ventricular system. The nerve cells in the central nervous system showed no particular changes.

3-e. Histological changes in other organs and tissues

Histological changes which corresponded to scleroderma were not observed in the skin macro- and microscopically. The peripheral nerves and other organs (liver, kidney, heart, lung, spleen etc.) showed no remarkable changes, so far as examined lightmicroscopically.

But cytoplasmic inclusion bodies, entirely the same as those found in the skeletal muscles and choroid plexus epithelia of the brain ventricles, were also observed electron microscopically in the formalin-fixed tissues of the kidney, spleen, liver and heart which presented no abnormalities at lightmicroscopic level. The tissues examined had been stored in $10 \%$ buffered formalin ( $\mathrm{pH} 7.4$ ) solution for about one year. In the kidney, although the cytoplasmic inclusion bodies were occasionally found in the tubular epithelia, glomerular epithelial cells contained impressively large numbers of bodies, which was reminiscent of Fabry's disease. No inclusion bodies were found in mesangium and endothelium of glomeruli. These inclusion bodies were also observed, although small in number, in the splenic lining cells, liver parenchymal cells and myocardial cells as well as the endothelia of blood vessles. 

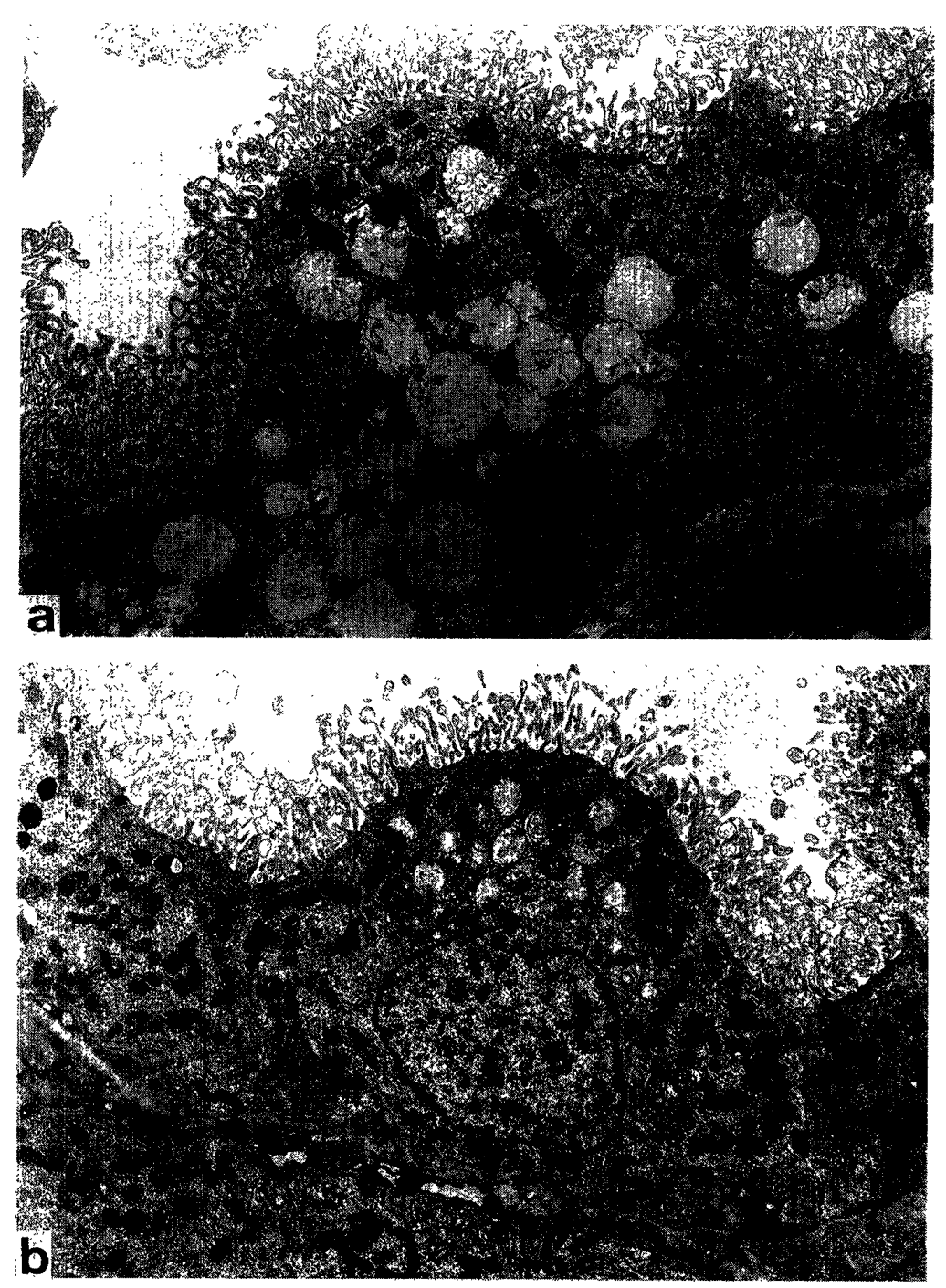

Photo 5 -a, b. Electron micrographs of epithelial cells of choroid plexus in experiment $2(\mathrm{~A})-75 \mathrm{mg} / \mathrm{kg}(5-\mathrm{a})$ and $50 \mathrm{mg} / \mathrm{kg}$ (5-b). Various degrees of cytoplasmic vacuolization which seems to be resulted from dilatation of smooth endoplasmic reticulum are seen and electron-dense inclusions, though less frequent than skeletal muscle, are also seen. The scale is 2 $\mu \mathbf{m}$.

\section{DISCUSSION}

The main toxicity of epoxy resin has been regarded as the irritation effects so far. In fact, most of epoxy resin components which include curing-agent show more or less irritation effects while systemic toxic effects are uncommon in man (Hine et al., 1981). But, in recent years, potentiality of some epoxy resin to cause such symptoms or signs 


\section{Susumu OHSHIMA et al.}

like collagen disease as scleroderma in industrial workers has been suggested (Yamakage et al., 1980). On the other hand, generation of symptoms like scleroderma caused by handling a variety of organic solvents was also reported (Yamakage et al., 1982). It is required, therefore, to clarify the relationship between the generation of symptoms like collagen disease and the industrial intermediate materials such as epoxy resin or organic solvents.

About the epoxy resin components containing the curing-agent which we studied the toxicity in our experiments, several investigations have been made in some institutes up to now (Matsusita, T. et al., 1983, Nakano, Y.et al., 1982). But the symptoms observed in the workers have not been reproduced in the animals by the application of suspected agents to the skin, except local irritation effects. It was shown, however, that the amine-curing agent for the resin could induce the symptoms like scleroderma in the mouse skin by its repeated intraperitoneal injections (Yamakage et al., 1980, Ishikawa et al., 1980). The invasion route of the agent in the work place is considered to be through the skin or by way of the respiratory tract, but it remains to be proved why the agent applied to the skin shows no more than local irritation effects on animals. Probably, its complicated effects with the volatile solvents in case of taking it through the respiratory tract or some differences in metabolic pathway might be responsible for the discrepancy of toxic effects between the human and the animal. But our findings as well as Yamakage et al. show that this agent is the very causative agent which induced the toxic signs in the workers.

The pathological changes of the skeletal muscles represented in our experiments suggest strongly the cause and effect relationship between this agent and the clinical muscular signs in the field workers. Namely, the workers showed more or less muscle symptoms and signs such as weakness or atrophy of the muscle besides the scleroderma-like changes of the skin (Yamakage et al., 1980). The main pathological changes in the rat skeletal muscle in our experiments were mixture of atrophy, degeneration and regeneration of muscle fibers with increase of interstitial cells (fibroblasts and so on). Correstonding to these changes, such clinical abnormalities as weakness of the limb muscle and increased values of GOT, CPK and creatine were revealed. These findings are common to other inflammatory myopathies (DeGirolami and Smith, 1982). In our experiments, animals showed rather slight inflammatory cell infiltration, while increase of interstitial cells was relatively marked in higher dosage groups. So, the present changes in the skeltal muscles may differ from these of polymyositis. On the other hand, round-shaped lamellar bodies in the sarcoplasm observed have been also found in so-called inclusion body myositis of which clinical signs differ from dermatomyositis or polymyositis (Carpenter et al., 1978, Julien et al., 1982, Eisen et al., 1983). Inclusion bodies in the muscle fibers were also observed in other toxic myopathies such as chloroquine-induced myopathy as well as in the inclusion body myositis (Julien et al., 1982, Rewcastle and Humphrey, 1965). Inclusion body myositis is characterized morphologically by basophilic lined vacuoles which contain polymorphic osmiophilic whorls 
and intracytoplasmic or intranuclear filamentous inclusions (Eisen, et al., 1983). In case of chloroquine-induced myopathy, numerous vacuoles are observed in paraffin sections of muscle fibers and optically dense structures are also seen in osmium fixed epon sections of muscle fibers. They are both proved to be myeloid bodies electronmicroscopically (MacDonald and Engel, 1960). The size and distribution of these vacuoles or myeloid bodies have much resemblance to those in our experiments. The changes in the rat muscles, therefore, have much similarity rather to such myopathies as inclusion body myositis or toxic myopathies than to polymyositis. Those bodies might be considerd to be formed by accumulation of some lipids in lysosomes, because of the considerable morphological similarity with other inclusion bodies in various human diseases and drug-induced lipidosis. Namely, such inclusion bodies are often encountered in such lipid storage lysosomal diseases as Tay-Sachs disease or Fabry's disease (Johannessen, 1978), or drug-induced phospholipidosis (Tashiro et al., 1983, Abraham and Hendy, 1970, Hruban et al., 1972). In cases of these lipidosis, some lipids accumulate in the lysosomes in the consequence of defficiency or inhibition of some enzymes participating in lipid metabolism, and it is evidenced that lipid content increases frequently in various organs (Tashiro, et al., 1983). Unfortunately, as qualititative and quantitative lipid analyses of the muscles have not been yet carried out in our experiments, it could not be defined whether the inclusion bodies in our experiments are of the same nature as those bodies in such lipidosis. It's necesarry to clarify in future the biochemical nature of the bodies in our case and to consider the meaning of an appearance of these bodies in the skeletal muscles. It should be said that this lipidosis -like changes seem to be rather systemic than limited to the muscle, because the bodies were also seen in other organs and tissues such as the brain choroid plexus, kidney, spleen, liver and heart.

The pathological changes in the brain choroid plexus caused by this agent were observed for the first time in our experiments, but the significance is still unclear, although non-existence of blood-brain-barrier in choroid plexus might be responsible for the toxic effect on it. It has been reported that the vacuolization of choroid plexus epithelium similar to that in our experiments was induced by some tertiary amines such as piperamide maleate (Levine, 1977). A series of tertiary amines were examined in animals and it was concluded that the lesion was resulted from chemical affinity between the tertiary amines and some components of the choroid plexus epithelium. But the agent we examined belongs to primary amine which has two amino-groups in a molecule. The degeneration of the choroid plexus epithelium might be caused not only by tertiary amines but also by primary amines although there is possibility that addition or eleimination of $\mathrm{N}$-alkyl group takes place in organism. The choroid plexus of the brain has such functions as production and secretion of cerebro-spinal fluid (Masuzawa and Sato, 1983), and the degeneration of epithelial cells of the choroid plexus may, therefore, have somewhat effects on the central nervous system. But, neither neurological signs were observed in the animals follwing administration of the agent nor 


\section{Susumu OHSHIMA et al.}

particular lesions were found, lightmicroscopically at least, in nerve cells in the brain and spinal cord in our experiments.

The pathological changes of the skeletal muscles observed in our experiments are probably myogenic, judging from the pattern of muscle lesion. But the possibility that these changes were secondary to the nerve damage cannot be completely ruled out. It is also necesarry to carry out histochemical examination and electronmicroscopical observation of the peripheral nervous tissue with the neuro-muscular junction.

In conclusion, our subacute experiments have revealed that the amine-curing agent for epoxy resin, bis(4-amino-3-methylcyclohexyl)methane, could exert some toxic effects, including myopathy-like changes similar to inclusion body myositis or chloroquine-induced myopathy and vacuolar degeneration of the brain choroid plexus. Though the specificity of its toxicity on the skeletal muscle and the brain choroid plexus is questionable at present, its chemical structure and pharmacological activty might be responsible for the specificity of the effects. Ultrastructural observations of the skeletal muscle, brain choroid plexus and other tissues suggested morphologically that the lesion caused by the agent might be a kind of systemic lipidosis. The relation between this systemic effect and the tissue-specific lesion caused by the agent is also unclear, but probably both might be the separate effects. Further investigations on the toxic effects after more prolonged exposure to the agent and on the ultrastractural changes in various tissues are being undergone now.

\section{REFERENCES}

Abraham, A. and Hendy, R. J. (1970) ; Irreversible lysosmal damage induced by chloroquine in the retinae of pigmented and albino rats. Exp. Mol. Path., 12, 185-200.

Benke, B. (1976) : Mass occurence of multilamellar bodies in myopathy.. Virchows Arch. B. Cell Path., 20, 77-84.

Carpenter, S., Karpati, G., Hellar, I. et al. (1978): Inclusion body myositis : A distinct variety of idiopatic inflammatory myopathy. Neurology, 28, 8-17.

Degirolami, U. and Smith, T. W. (1982) : Pathology of skeletal muscle disease. Am. J. Pathol., $107(2), 235-276$.

Eisen, A., Berry, K. and Gibson, G. (1983): Inclusion body myositis (IBM). Myopathy or neuropathy? Neurology, 33, 1109-1114.

Hine, C. H., Rowe, V. K., White, E. R. et al. (1981) : Epoxy compunds. Chapter 32. In Patty, Industrial hygine and toxicolgy (D. W. Irish eds.). Vol. 2, p 2141-2257, Interscience, New York.

Hruban, Z., Slesers, A. and Hoplins, E. (1972) : Drug-induced and naturally occuring myeloid bodies. Labor. Invest., 27, 62-70.

Ishikawa, H., Yamakage, A., Kitabatake, M. et al. (1980) : Detection of sclerosis-inducing glycosaminoglycan in the skin of amine-induced experimental skin sclerosis. Dermatologica, 161, 145-151.

Johannessen, J. V. (1978) : Electron microscopy in human medicine, Vol. 2, Cellular pathology and metabolic and storage diseases. (J. V. Johannessen eds.) p. 176-193, McGraw-Hill, 
England.

Julien, J., Vital, Cl., Vallet, J. M. et al. (1982) : Inclusion body myositis. J. Neurol. Sci., 55, 15 -24 .

Levine, S. (1977): Degeneration of choroid plexus epithelium induced by some tertiary amines. In Neurotoxicolgy (L. Roizin, H. Shiraki and N. Grcevic, eds).p.419-425, Raven Press, New York.

Macdonald, R. D. and Engel, A. G. (1970): Experimental chloroquine myopathy. J. Neuropathol. Exp. Neurol., 29, 479-499.

Masuzawa, T. and Sato, F. (1983): The enzyme histochemistry of the choroid plexus. Brain., 106, 55-99.

Matsusita, T., Aoyama, K., Nomura, S. et al. (1980) : An experimental study of scleroderma-like disease by epoxy resin and methylchloroform. Jap. J. Ind. Med., 22, 614.

Nakano, Y., Hara, I., Ando, T. et al. (1982) : Approach to induction of scleroderma-like disorder with epoxy resin KE-5301 and methylchloroform. Proceedings of Osaka prefectural institute of public health, edition of industrial health. Vol.20, 1-7.

Ohshima, S., Shibata, T., Sasaki, N. et al. (1984) : Subacute toxicity of amine-curing agent for epoxy resin. Jap. J. Ind. Med., 26(3), 197-205.

Rewcastle N. B. and Humphrey J. G. (1965) : Vacuolar myopathy. Arch. Neurol., 12, 570-582.

Tashiro, Y., Watanabe, Y. and Enomoto, Y. (1983) : Experimental phospholipidosis induced by 4, 4'-diethyl-aminoethoxyhexestrol. Acta Pathol. Jpn., 33(5), 929-942.

Yamakage, A., Ishikawa, H., Saito, Y. and Hattori, A. (1980) : Occupational scleroderma-like disorder occuring in men engaged in polymerization of epoxy resin. Dermatolgica, 161, $33-44$.

Yamakage, A. and Ishikawa, H. (1982): Generalized morphea-like scleroderma occuring in peaple exposed to organic solvents. Dermatologica, 165, 186-193. 